\title{
2 \\ DESREGULACIÓN ECONÓMICA EN EL AGRO \\ EN LOS 90S. UN ANÁLISIS SOBRE SU \\ PROBLEMATIZACIÓN PÚBLICA Y PRIVADA \\ A PARTIR DEL ESTUDIO DE CASOS
}

\author{
Tomás Palmisano (•) \\ Instituto Gino Germani - \\ Universidad de Buenos Aires
}

\section{RESUMEN}

Durante el período neoliberal, el Estado reconfiguró su forma de accionar en diversos espacios de la sociedad. En ese contexto, la promulgación del Decreto de Desregulación Económica 2284 de 1991 tuvo un fuerte impacto en el sector rural argentino. Por ello analizamos el proceso de problematización del tema por parte de diversos actores, la toma de postura del Estado materializada en el texto del Decreto y algunas de las reacciones que suscitó, a la luz de los aportes clásicos de Oszlak y O’Donnell. Así ahondamos en la comprensión de las estrategias y formas de comunicación que se articulan en el proceso de adopción de una política pública. En términos metodológicos, analizamos el contenido de una recopilación de discursos aparecidos en la prensa gráfica especializada durante los años 1990 y 1991 y trabajamos con técnicas de análisis del discurso el cuerpo del Decreto 2284 y publicidades empresariales. Este artículo concluye que aun cuando la posición a favor de la desregulación estatal del sector agropecuario tenía consenso entre los actores hegemónicos, la intensidad de la política pública trascendió sus expectativas potenciando profundas transformaciones económicas, sociales y políticas.

\section{PALABRAS CLAVE:}

neoliberalismo, sector agropecuario, agronegocio, acciones estatales.

RECEPCIÓN: 06/04/17

ACEPTACIÓN FINAL: 29/09/17 